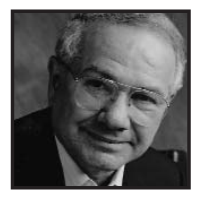

\title{
Commentary:
}

\section{What Education Can Learn From the Arts}

\section{Elliot Eisner, Stanford University}

\section{ABSTRACT}

The arts have typically been regarded as non-cognitive activities that are often thought to be more ornamental than useful. This paper examines prevalent assumptions about the arts and identifies forms of thinking that the arts promote. It is argued that far from being merely decorative, the arts stimulate, refine, and convey meanings that cannot be expressed in any other form of representation. The recognition of the demands and the contributions that the arts make is of fundamental importance in justifying the place of the arts in our schools, that is, as being central, rather than peripheral educational accomplishments. This paper identifies a number of the forms of thinking that the arts promote as a basis for building a case for their presence in our schools by regarding them as being substantially more than of marginal importance.

Why, man, he doth bestride the narrow world

Like a Colossus; and we petty men

Walk under his huge legs and peep about

To find ourselves dishonorable graves.

Men at some time are masters of their fates:

The fault, dear Brutus, is not in our stars,

But in ourselves, that we are underlings.

(Shakespeare, 1, ii, 135-141) 
ince the turn of the century--the $20^{\text {th }}$ century--American schools have been impacted by a pedagogical and organizational paradigm built upon methodologies of the physical sciences. Schools were regarded as arenas within which the ideas of scientific technology could find wide application. In this model, the specification of ends and the search for ideal means relevant to the achievement of those ends was a dominant aspiration. Just reflect on the work of Franklin Bobbitt in the 1920s, the growth of the behavioral objectives movement in the 1950s, and most recently, the preoccupation with standards as a way to achieve the ends that were formulated. The tacit aspiration of researchers and some practitioners, particularly school administrators, was to find a set of methods that would efficiently and effectively help us to achieve our most important goals.

This paradigm, a scientistic paradigm, was much more interested in certainty in methods than in the surprises that some methods would yield. It was more concerned with measurement than with meaning, and, at times, its metaphors likened education to a business.

In this orientation, the arts were often marginalized. They are difficult to measure, and they harbor values that some believed to be problematic. At their best, the arts were nice to have in schools but not necessary. Even though the arts are considered a core subject in recent legislation pertaining to the No Child Left Behind initiative currently adopted in many American schools, in the reality of the school day, they are often hard to find.

But what if we looked to the arts as being not merely recipients of policies made in light of a technological paradigm, but rather, as a source of both insight and practice that had something special to offer those interested in school improvement. Maybe it is the case that the arts have something to teach those whose paradigm is closer to educational engineering than it is to aesthetics. Maybe there is a story to be told that would capture the imagination of a public eager to find genuinely satisfying educational experiences for their children.

This paper was written to describe what it is that education can learn from the arts that is relevant to the improvement of our schools. Just what do the arts have to teach education? And why is what they have to teach educationally important? My hope is that what I have to say will enable those who seek extrinsic reasons for justifying the arts in the schools will find a rationale for the arts that they might regard as being self-justifying. 
1. Education can learn from the arts that form and content cannot be separated. How something is said or done shapes the content of experience.

It has long been held that form and content are distinct phenomena and that one can modify the form of an object or event without changing its content. I argue that content and form coexist and must, of necessity, define each other. To change the form of a form is to change the quality of the experience that it makes possible. The quality of experience that a form makes possible is what the content of the form is.

What does this mean for education? It means this. It serves as a reminder that how something is taught, how curricula are organized, and how schools are designed impact upon what students will learn. These "side effects" may be the real main effects of practice.

2. Education can learn from the arts that everything interacts; there is no content without form and no form without content.

The point of this idea pedagogically is to acknowledge that when the form is changed into an object or an event, so too, is the quality of life it engenders. When the content of a form is changed, so too, is the form altered. Form and content are like two sides of a coin. One cannot have one without the other.

There are no separate parts in a whole. What, for example, a color looks like depends upon the colors around it. The same is true in teaching. We call this interaction.

The concept of interaction is as fundamental in education as it is in all human states of affairs. What is large and what is small depends upon what one is comparing it to. What is hard and what is soft depends on the hardness of the hard and the softness of the soft. Soft can be hard in some contexts and can be soft in others. This is because interaction is a condition of experience.

In teaching, whether a teacher is considered to move swiftly or to move slowly depends not only upon the teacher's rate of speech but also on what 
the student brings to the occasion. For some students, swift is slow, and for others, slow is swift. It is the character of the interaction that defines our experience.

3. Education can learn from the arts that nuance matters. To the extent to which teaching is an art, attention to nuance is critical.

It has been said that the devil lives in the details. It can also be said that the aesthetic lives in the nuances that the maker can shape in the course of creation. How a word is spoken, how a gesture is made, how a line is written, and how a melody is played, all affect the character of the whole. All depend upon the modulation of the nuances that constitute the act.

Musicians "live in their nuances."There are dozens of ways to play a pizzicato on a violin, but what any particular violinist does with the pizzicato depends upon what he or she does with the nuances that constitute that particular rendition of the music.

4. Education can learn from the arts that surprise is not to be seen as an intruder in the process of inquiry, but as a part of the rewards one reaps when working artistically.

In our technically oriented, control-focused society, we tend to regard surprise as an inability to predict. It is. But surprise in the course of work is also the result of securing a new insight--one that was hitherto unexpected. No surprise, no discovery, no discovery, no progress. Educators should not resist surprise, but create the conditions to make it happen. It is one of the most powerful sources of intrinsic satisfaction.

5. Education can learn from the arts that slowing down perception is the most promising way to see what is actually there.

It is true that we have certain words to designate high levels of intelligence. We describe somebody as being swift, or bright, or sharp, or fast on the 
pickup. Speed in its swift state is a descriptor for those we call smart. Such folks are a quick read. Yet, I would argue that one of the qualities we ought to be promoting in our schools is a slowing down of perception: the ability to take one's time, to smell the flowers, to really perceive in the Deweyan sense, and not merely to recognize what one looks at.

Recognition by contrast, Dewey (1934) pointed out, is about attaching a label to an object or event: this is an automobile; that is a wagon; this is an elm tree; that's a pine. The task of recognition has to do with a classification and assignment of a label that stands for the event. Much of early reading instruction is of this type.

What perception entails is not so much classification or categorization, but a savoring, a qualitative exploration of a variety of qualities--qualities that constitute the qualitative wholeness of the object or event being perceived. Dewey argued, and I endorse his argument, that learning how to slow down perception is one of the primary ways in which one can enrich one's own experience. For slowed-down perception to become a habitual attitude, it will require a cultural change in America. I do not know whether or not we are ready for such a change. I do know that much of human experience is dissipated or weakened because of the absence of time that needs to be taken to see, to really see.

6. Education can learn from the arts that the limits of language are not the limits of cognition. We know more than we can tell.

In common parlance, literacy refers essentially to the ability to read and to write. But literacy can be re-conceptualized, and I propose to do so, as the creation and use of a form of representation that will enable one to create meaning--meaning that will not take the impress of language in its conventional form. In addition, literacy is associated with high-level forms of cognition. We tend to think that in order to know you have to be able to say. I would argue that the limits of language in no way define the limits of cognition. As Polanyi (1969) reminds us, we know more than we can tell. The implications of that idea are profound for education. If taken seriously, it would expand our conception of what knowing entails. It would recognize the diverse ways in which people can be literate, or, should I say, be multi-literate. Language used in the service of the poetic is quite different 
from language used in the service of the literal. One can be literate in one form and illiterate in the other. What schools need to attend to is the cultivation of literacy in its many forms. Each form of literacy provides another way to be in the world, another way to form experience, another way to recover and express meaning.

7. Education can learn from the arts that somatic experience is one of the most important indicators that someone has gotten it right.

Related to the multiple ways in which we represent the world through our multiple forms of literacy, is the way in which we come to know the world through the entailments of our body. Sometimes one knows a process or an event through one's skin. As Langer (1979) once commented, the senses are our first avenues to consciousness. There is nothing in the head that was not first in the hand. Somatic experience is body knowledge: a sense of rightness of fit, an ability to discriminate without being able to articulate the conditions that make it possible. The body knows and forms the basis for intuition. To require the logical description or the logical argument for a claim about a state of affairs is to expel the poetic from what can be known. The evidence for what we know almost always supersedes and expands to more than what one can say about it.

8. Education can learn from the arts that open-ended tasks permit the exercise of imagination, and an exercise of the imagination is one of the most important of human aptitudes. It is imagination, not necessity, that is the mother of invention.

Imagination is the source of new possibilities. In the arts, imagination is a primary virtue. So it should be in the teaching of mathematics, in all of the sciences, in history, and, indeed, in virtually all that humans create. This achievement would require for its realization a culture of schooling in which the imaginative aspects of the human condition were made possible. We ought to be helping our students discover new seas upon which to sail rather than old ports at which to dock. We need schools where tasks are sufficiently open-ended allowing students to place their thumbprint upon their work without a sense of redundancy. It's an ambitious aim I am after, but one, I think, that is critical in the long run for the well-being of the planet. 
My aim in these brief comments is to open up and explore the implications the arts have for the aims and conduct of education. Clearly the list of features I have identified does not exhaust the dimensions of schooling and educational practice that can be identified. It is an effort to provide a set of leads that can be pursued and explored. In a sense, this effort represents the beginning of a kind of paradigm supplement rather than a paradigm shift. By that, I mean, I am not interested in substituting one paradigmatic model for another, but rather, am interested in adding to the pantry of possibilities of new methods and views that may have important pedagogical consequences. To the extent to which our practices reflect our beliefs, changes in beliefs ought to manifest themselves at least, to some degree to changes in practice. That is my hope.

The arts are not typically seen as a valued resource for re-conceptualizing educational work. Tradition has assigned the arts to a marginal position in the armamentarium we use to negotiate the educational world. This need not be the case. My hope is that the options I have identified are sufficiently attractive to draw scholars together to explore their practical implications in real-life situations. The practical utility of these "lessons" from the arts remain to be tested. When the going gets tough we should remember that there are few higher compliments that one can assign to an individual for his or her work than to say that it is a "work of art." Indeed, a work of art may represent the highest form of human achievement, again, whether in the fine arts themselves or in the sciences.

To help students treat their work as a work of art is no small achievement. In the process people become artists. Given this conception we can ask, how much time should be devoted to the arts in school? The answer is clear: all of it.

\section{Notes}

An earlier version of this commentary was presented at the National Art Education Association Convention in New Orleans, Louisiana, 2008. Reprinted with permission. 


\section{References}

Dewey, J. (1934). Having an Experience. In Art as Experience, 36-59. New York: Perigree. Reprinted in 2005.

Langer, S. (1979). Philosophy in a new key: A study in the symbolism of reason, rite, and art ( $3^{\text {rd }}$ ed.). Cambridge, MA: Harvard University Press. Original work published in 1942.
Polanyi, M. (1969). Knowing and being. London, UK: Rutledge \& Kegan Paul.

Shakespeare, W. (1911). Julius Caesar. In W. G. Clark, \& W. A. Wright (Eds.), Complete works of William Shakespeare (pp. 949-978). New York: Cumberland. Original work published in 1623.

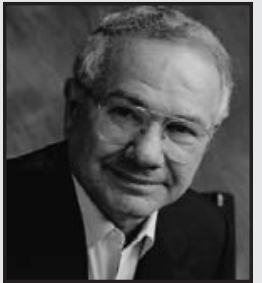

Elliot W. Eisner is the Lee Jacks Professor of Education and Professor of Art at Stanford University. Professor Eisner was trained as a painter at the School of the Art Institute of Chicago and studied design and art education at the Institute of Design at the Illinois Institute of Technology. He received his Ph.D. from the University of Chicago.

Professor Eisner's contributions to education are many. He works in three fields: arts education, curriculum studies, and qualitative research methods. He has been especially interested in advancing the role of the arts in American education and in using the arts as models for improving educational practice in other fields. He is the author or editor of sixteen books addressing these topics, among them, Educating Artistic Vision, The Educational Imagination, The Enlightened Eye, Cognition and Curriculum, The Kind of Schools We Need, and, most recently, The Arts and the Creation of Mind. He has lectured on issues critical to education throughout the world.

Professor Eisner has received many prestigious awards for his work, among them a John Simon Guggenheim Fellowship, a Senior Fulbright Fellowship, the Jose Vasconcelos Award from the World Cultural Council, the Harold McGraw Prize in Education, the Brock International prize in Education, and the Grawemeyer Award in Education from the University of Louisville. In addition, he has received six honorary doctorates from institutions around the world. 